\title{
Putting the Burden of Proof in Its Place: When Are Differential Allocations Legitimate?
}

\author{
Tim Dare \\ University of Auckland \\ Justine Kingsbury \\ University of Waikato
}

\begin{abstract}
It is widely assumed that legitimate differential allocations of the burden of proof are ubiquitous: that in all cases in which opposing views are being debated, one side has the responsibility of proving their claim and if they fail, the opposing view wins by default. We argue that the cases in which one party has the burden of proof are exceptions. In general, participants in reasoned discourse are all required to provide reasons for the claims they make. We distinguish between truth-directed and non-truth-directed discourse, argue that the paradigm contexts in which there are legitimate differential allocations of the burden of proof (law and formal debate) are non-truth-directed, and suggest that in truth-directed contexts, except in certain special cases, differential allocation of the burden of proof is not warranted.
\end{abstract}

\section{Introduction}

To have the burden of proof is to be rationally required to argue for or provide evidence for your position. To have a heavier burden than an opponent is to be rationally required to provide better evidence or better arguments than they are required to provide. Many commentators suggest that differential or uneven

Tim Dare is Head of the Department of Philosophy and also teaches in the Law School at the University of Auckland. His research interests include philosophy of law, professional ethics, and philosophical methodology.

Justine Kingsbury works in the Department of Philosophy and Religious Studies at the University of Waikato. Her areas of research include philosophy of mind, philosophy of biology, philosophical methodology, informal logic, and aesthetics. 
distribution of the burden of proof is ubiquitous. In reasoned discourse, the idea goes, it is almost always the case that one party must prove the claim at issue to prevent the opposing view from winning by default. The following passage is typical of the sort of thing one finds in critical thinking textbooks:

It is rare, outside legal and quasi-legal contexts, for the burden of proof on one side of an argument to be recognised formally. Yet, the implicit idea behind it is found in all reasoning. One person has a more demanding job of proving a point and, if they fail, then an alternative position remains the preferred one. One person must provide more evidence, must positively show their conclusion to be true. (Allen 2004, 81)

This is not just something philosophers say for pedagogical reasons in introductory critical thinking texts. There is a long philosophical tradition of sheltering behind differential allocations of the burden of proof. In the face of Philonus's sustained critique, Berkeley's dogmatist Hylas concedes that he can give no good reason for his belief in matter, but he announces "as long as there is no absurdity in supposing [it], I am resolved to believe as I did, till you bring good reasons to the contrary." Philonus responds indignantly that Hylas has the burden of proof the wrong way around: "the proof" he insists, "should lie on him who has the affirmative" (Berkeley 1971, 241-42). Skeptic and dogmatist disagree on where the burden of proof lies, but they agree that it should be allocated differentially. A century or so later Thomas Reid insisted that there were principles and beliefs "common to philosophers and to the vulgar, which need no explication, [or] proof": "All men that have common understanding, agree in such principles; and consider a man a lunatic or destitute of common sense, who denies them or calls them into question" (Reid 1863, 230-34). Such beliefs are justified, Reid maintains, until shown to be unjustified. More recently, in the philosophy of religion, Michael Scriven argues that "we need not have a proof that God does not exist in order to justify atheism. Atheism is obligatory in the absence of any evidence for God's existence" (Scriven 1966, 88). And, discussing the normative significance of the burden of proof, Juha Räikkä tells us that the "intelligent arguer attempts to avoid the burden of proof and achieve a position in which she is presumed to be right until proven otherwise" (Räikkä 2005, 228).

We think a quite general methodological mistake lies behind these views about the burden of proof. ${ }^{1}$ Far from being ubiquitous, legitimate differential allocations of the burden of proof are exceptional. In our view, whether differential allocations are warranted depends on the aim of the inquiry or piece of discourse in question, and on whether or not differential allocation promotes that aim. Most generally, we distinguish between non- 
truth-directed and truth-directed practices. The clearest examples of legitimate differential allocation are found in certain types of practice in which truth is not the primary aim, such as formal debates and, we will argue, legal discourse. We suspect that many commentators who think otherwise mistakenly regard certain types of non-truth-directed practice as paradigmatic rather than exceptional.

We begin with some preliminary remarks. First, empirical studies suggest that many of those involved in conversational arguments do systematically differentially allocate the burden of proof. Jeremy Bailenson reports, for instance, that experimental subjects tend to believe that the initiator of such an argument has the burden (Bailenson 2001, 36). Such studies are interesting but do not bear directly on our point, since we argue that people often mistakenly allocate the burden of proof. The fact that it is widely believed that differential allocations of the burden are legitimate, and even the fact that interlocutors often accept the burden does not show that differential allocation is methodologically legitimate. Second, we will often speak as though there is a single allocation of the burden, as though it were properly allocated to one or the other party or position at the outset and remained there throughout the debate or discussion. We recognize that in many, perhaps most, contexts in which the allocation of the burden of proof is in question, the burden, or the weight of the burden, might pass from position to position, person to person, as a dialogue proceeds. However, we do not believe that our analysis is troubled by this feature of discourse and debate. At each step, we believe, differential allocation of the burden is legitimate only if it makes it more likely that the dialogue will achieve its aim. And if the aim is truth, then (we will argue) this will be so only in certain exceptional cases. Finally, our arguments may be taken to support a stronger or weaker conclusion. The weaker alternative is the negative claim that those who assume the ubiquity of legitimate differential allocations of the burden of proof are mistaken. The stronger, positive conclusion is that the legitimacy of differential allocations turns on whether or not the inquiry or discourse in question is truth directed and, in cases in which it is, whether differential allocations are truth conducive. We believe that even the weaker conclusion is a sufficient departure from orthodoxy to warrant philosophical attention, though we hope to go further and to offer compelling grounds for accepting the stronger one.

\section{The Burden of Proof and Non-Truth-Directed Practices}

Legal discourse is often taken as a paradigm of the legitimate differential distribution of the burden of proof. Räikkä, for instance, says: 
The question of who has the burden of proof is often important in practice. We must frequently make decisions and act on the basis not of conclusive evidence but of what it is reasonable to presume true. A paradigmatic example of this is of course the trial, in which a person is presumed innocent and must be freed unless proven guilty. (Räikkä 2005, 228)

Formal debate is another practice in which the burden of proof is explicitly differentially allocated between the views at issue. In the standard format, there are two teams, and topics are chosen that allow two contrasting views. The teams take opposite sides of the topic: one defending the affirmative; the other, the negative. Each team puts forth a case for their side, addressing points made by the other side in a formal structure of assertion and reply. Each team aims to convince an adjudicator that they have put a better case to the audience than their opponents have. A typical set of debating society guidelines includes this sort of advice:

Rebuttal is vital. An argument, however weak, stands until it is rebutted.... Adjudicators cannot regard an argument as knocked down until the opposition has rebutted it effectively. If a team makes an error of fact or logic, the adjudicator cannot penalise them for it unless the other team points out the error.... (Auckland Debating Association Guidelines 2002)

In our view, although law and debates are paradigm cases of the legitimate differential allocation of the burden of proof, they are not paradigm cases of reasoned discourse. Consequently it is a mistake to generalize from the legitimate differential allocation of the burden in these cases to the ubiquity of such legitimate allocations. Their peculiarity, we believe, lies in the fact that neither legal discourse nor formal debate is primarily truth directed.

Take debate first. The opposition has the burden of showing errors of fact or logic in a team's case. Unless the burden is met, the claims stand. Notice how peculiar the debating guideline would be were we interested in the truth about the topic under debate. In those circumstances, errors of fact or logic would undercut an argument. They do not do so in the context of the formal debate because we are not concerned with the truth of the matter at issue. Instead, debates compare the performance of each team relative to that of the other. A team wins if they have put a better case than their opponents, no matter how poor that case is relative to the facts of the matter. We allocate the burden of proof between the teams in ways we know are not truth conducive, because we are concerned not with truth, but with rhetoric, entertainment, and the skills of team members at noticing and responding to the flaws and strengths of the argu- 
ment actually presented (as opposed to the best argument that could be presented).

The law might seem a more challenging case. Unlike the debate, it is not a game and it is more tempting to think-given the importance of the matters that ride on legal findings-that it is primarily concerned with truth. Certainly, as Räikkä and many others point out, the law specifies very clear allocations of the burden of proof. In most penal law, the burden of proof lies with the accuser. Until an accusation has been proven to the standard set by the law, the accused person is presumed to be innocent and is entitled to simply stand on this default assumption, leaving it entirely to the prosecutor to make the case against her. There are good reasons for the legal presumption of innocence. Findings of criminal guilt may have significant consequences, most obviously loss of default liberties and rights. Since we regard those liberties and rights as important, we place a weighty burden on those who seek to have them removed or limited. As the legal saw has it, "better a hundred (in truth) guilty people go free than one (in truth) innocent person is jailed." Now consider Räikkä's description of the presumption of innocence: the innocence of the accused person, he writes, is "what it is reasonable to presume true" (Räikkä 2005, 228). We think this is a misleading account of what is going on in the legal case. The legal presumption of innocence does not amount to believing, until or unless the accused person is proven guilty, that they did not commit the crime. The law does not think (and nor should the rest of us) that the innocence of the accused person is what it is reasonable to presume to be true. Instead, the law acts as if the person were innocent, without taking a position upon whether they are so as a matter of fact.

We see evidence that the law is not primarily truth directed throughout the legal system, and especially clearly in cases in which courts refuse to consider evidence even while acknowledging that had it been considered it might have helped to establish the truth about the matter before them. Chris Fowlie, President of New Zealand's National Organisation for the Reform of Marijuana Laws, was charged with possession after police found marijuana in his pocket. The court found the search had been illegal, conducted without reason as part of a general sweep rather than, as the police had claimed, "by reason of [the officers] detecting a smell of cannabis emanating from the Defendant." "I conclude," said the judge, "that even had the evidence been such as to prove beyond reasonable doubt all the requisite formalities ... the search conducted of $\mathrm{Mr}$ Fowlie was unreasonable and the evidence obtained thereby should be regarded as inadmissible. The charge is dismissed" (Police v Fowlie).

Fowlie is typical of cases in which courts refuse to accept evidence gathered illegally even while acknowledging its proba- 
tive value. Just as in the debate case, this would be peculiar if the legal proceedings were solely or even primarily interested in truth. If that were the case, probative value might be expected to trump concerns about the manner in which the evidence was obtained, which could after all be dealt with in some other way: the Fowlie court might have accepted the evidence that Mr. Fowlie possessed cannabis and recommended proceedings against the police under the legislation they breached in searching him. ${ }^{3}$ When they exclude evidence rather than take some such alternative route, the courts in these cases show themselves to be interested less in truth than in requiring that prosecutors comply with the law, or in discouraging certain means of evidence-gathering.

It might seem that law and debate are but particular instances of a more general truth-conducive strategy. In debate and in law, there is a clear division of labor between the parties and the views on offer. Each side has the responsibility of defending their view and no responsibility for advancing the cause of their opponents, or for moving understanding of the topic toward the truth. It is often thought that adversarial systems of this kind are truth conducive. Generations of common lawyers have been raised on the declaration in Wigmore on Evidence that cross-examination, one of the prime courtroom manifestations of the adversarial system, is "the greatest engine ever invented for discovering the truth" (Wigmore 1976, §1367). But counterexamples are legion. The legal profession abounds with great cross-examiners whose status turns precisely on their ability to cast doubt on the testimony of truth-telling witnesses. ${ }^{4}$ It seems inherently unlikely that a system that at least occasionally not only allows but even requires advocates to take advantage of oversights in their opponent's case, to withhold probative evidence (such as admissions from their clients), and the like, would be especially efficient at seeking truth. That is no criticism of the law, however. The institutional arrangement that allows a party to focus entirely, blindly even, on the case for "their side" of the debate has less to do with the pursuit of truth than with a particular approach to the protection of rights.

Formal debate and legal discourse, we have argued, are not solely or primarily truth directed. If truth was their main aim, we suggest, differential allocation of the burden of proof would be illegitimate, because it is not truth conducive.

Formal debates and the law are both institutional cases. The burden of proof lies where it does in those cases because it has been put there by deliberate institutional design. But there are also noninstitutional cases in which the burden of proof seems to be legitimately differentially distributed. Consider, for example, cases in which safety is the issue. Tim lives in a twostory house. Every year a large plum tree deposits leaves in the 
upstairs gutters. Suppose Tim hires a handyman to clean them. When the handyman arrives he says he cannot complete the task since his ladder is too short. "Use mine," says Tim, anxious to have the job done. The handyman may well seek an assurance that the ladder is safe. Who has the burden of proof if Tim provides such an assurance? On some standard views of the burden of proof it matters who has made the assertion: since Tim is the one asserting that the ladder is safe, the burden of proving that to be so lies with him. We think that is the right allocation but for a different reason. In such cases we are not solely or even primarily interested in the truth of the claim about the ladder. Safety cases seem to us, perhaps surprisingly, to be broadly analogous with law. In both cases, although we are concerned with the facts of the matter (Is the ladder safe? Did the accused person commit the crime?), there is something else about which we are more concerned. In both cases, we are much more concerned about avoiding a particular kind of error than we are about finding out the truth: better a hundred gutters go uncleaned than one gutter-cleaner falls. Just as the presumption of innocence puts a heavy burden on those who would remove the rights of a defendant, so a "precautionary principle" places the burden of proof on views reliance on which would put others at risk. We do not mind being wrong, provided we err in the direction of caution.

\section{The Burden of Proof and Truth-Directed Practices}

In the previous section we discussed three contexts in which differential allocation of the burden of proof is legitimate: debates, legal argument, and safety cases. We suggest that these seemingly disparate examples are united by their focus on matters other than truth. In legal contexts differential allocation of the burden of proof makes it more likely that important default rights will be protected, and that is the primary concern of law; in debates differential allocation allows better display of the rhetorical skills of debaters, and that is what matters in debates; in safety cases differential allocation of the burden of proof makes it less likely people will be harmed, and that is what matters most in such cases. In each case, we have suggested that if the main aim of the inquiry had been truth, differential allocation of the burden of proof would have been illegitimate, because such an allocation is not in general truth conducive. (The "in general" caveat is important. We return to it below).

If we are right about this, differential allocation of the burden should (in general) be illegitimate in truth-directed practices. Suppose for the moment that philosophy and science are such practices. (Not everyone will happily accept this supposition. We discuss some alternative views at the end of 
this section.) There is, we suppose, a philosophical ideal of careful and unbiased consideration of all the available evidence and arguments. In philosophy, although it may sometimes be done, it is not considered respectable to know of but fail to acknowledge a good argument against one's view. Nor would we think someone a good philosopher who knew of a long-standing and otherwise unnoticed inconsistency in her theory but refrained from drawing attention to it. Even if it should turn out that most philosophers most of the time were highly partisan and ignored good arguments against their theories as often as they could get away with it, we would not think this was good philosophical behavior. They would be falling short of an ideal of receptiveness to evidence and argument. Note the contrast with law. The lawyer who argues that highly probative incriminating evidence should be excluded need not be falling short of any professional ideal. The judge who accepts that argument may be doing her job as she should. She would be open to censure if she did take such evidence into consideration.

Science may seem a more difficult case. How best to describe (or prescribe) proper scientific method is a contentious issue. For the moment, again, we proceed on the assumption that there is a widely accepted ideal of scientific reasoning broadly analogous to that we have attributed to philosophy. The aim of science, according to this (realist) ideal, is to discover the truth, and good science uses the best available methods for getting at the truth (though some truth-conducive methods may be rendered unavailable by, for example, ethical constraints). It is part of the ideal that a scientist should be open to the possibility of evidence that conflicts with her view and should be prepared to respond to apparent conflicting evidence by investigating whether the evidence holds up under scrutiny and modifying the view if it does. Giving a scientific theory the status of a default positionwhich is to say, assuming it to be true till the evidence for some competing view becomes overwhelming - seems to be one way of departing from this ideal. The default view is not held to the same standards of evidence as views that oppose it.

Consider the now notorious $H$. pylori affair, often advanced as an example of "bad science." In the early 1980s, it was accepted that peptic ulcers were caused by excessive gastric acid. The standard treatment was a bland diet and antacids. Later histamine (H2)-blockers were added to the regime. In 1983 two Australian gastroenterologists, Barry Marshall and Robin Warren, began reporting research linking gastritis and ulcers with a specific bacteria, Helicobacter pylori. Their work was summarily dismissed. Marshall's report of a statistically significant study in which only participants with gastritis and every participant with duodenal ulcers had $H$. pylori was one of only eight out of sixty-seven submissions refused inclusion in the Australian Gastroenterology Society's 1983 annual meeting. 
In 1988, Marshall and Warren performed a prospective, doubleblind trial comparing an antibiotic regimen with the standard ulcer therapy. The trial clearly demonstrated the role of $H$. pylori. However it was not until 1994 that the National Institutes of Health released a consensus statement accepting that antibiotics active against $H$. pylori should be the default ulcer therapy (Handler et al. 2004, 1109-11).

The $H$. pylori affair is taken to be paradigmatically bad science. The "no acid, no ulcer" consensus was treated as a default position, to be abandoned reluctantly, and only in the face of overwhelming evidence. ${ }^{5}$ The mistake, we suggest, was essentially getting the allocation of the burden of proof wrong, placing too heavy a burden on the bacterial theory.

This conclusion may itself seem to conflict with a piece of scientific orthodoxy. Even scientists who think errors were made in the $H$. pylori case are inclined to accept that the burden of proof is legitimately and disproportionately on the proponents of new theories. Advocates of the accepted view, the idea goes, need not suspend support for the view and return to the lab in response to every challenge. Those promoting new views must provide compelling evidence before anyone is required to take them seriously. We think there is something in this idea, but that cases in which it is legitimate to require especially good evidence for a new view are not really cases in which there is differential allocation of the burden of proof. It will often be true that those advancing new theories will have more work to do in support of their view than the proponents of a widely accepted view. But that may simply be because, in these cases, much of the work in support of the consensus has already been done. The advocate of the consensus view may be able to simply point to an accumulated body of evidence, already gathered and tested in the process of establishing the orthodoxy. There need be no differential allocation of the burden of proof here: merely a difference in what is required to discharge an equal burden. We claim, then, that when science is proceeding as it should, the differential allocation of the burden of proof in these "consensus" cases is merely apparent. Scientists may appeal to a consensus as a shorthand way of summarizing the evidence for an established view, but the fact there is a consensus does not of itself constitute evidence for the truth of a theory or proposition. ${ }^{6}$

Discussion in this section has proceeded on the supposition that philosophy and science are truth-directed practices. Antirealists of various kinds are likely to reject this supposition. Hilary Putnam rejects what he calls "metaphysical realism" in favor of a perspectival position according to which truth is relative to conceptual schemes (Putnam 1990). Van Fraassen's constructive empiricism (van Fraassen 1980) identifies empirical adequacy rather than truth as the goal of scientific theorizing 
(about unobservable entities). Others think that science aims not at truth but at instrumental success. All of these views are likely to lead their proponents to deny that science is a straightforwardly truth-directed practice. However, we think that even these antirealists would agree with most of what we say about philosophy and science. We could, we suggest, replace each occurrence of "truth" in the foregoing discussion with a particular theorist's preferred truth analogue (truth within a conceptual scheme, empirical adequacy, instrumental success, or the like), without undercutting the substance of our claims about the legitimate allocation of the burden of proof. All of these alternative conceptions of science and philosophy accept our description of the relevant parts of those practices. They accept, that is to say, ideals of receptiveness to evidence and argument, albeit relative to a truth analogue rather than to truth simpliciter, and so should accept our conclusions about the differential allocation of the burden of proof.

Some antirealist views may not be so easily accommodated. Radical social constructivists, for instance, think that the aim of scientific and philosophical inquiry is mere consensus and that any means of securing consensus is legitimate. Argument, on this view, is simply one form of rhetoric (see, for example, Woolgar 1988, 26). The most radical adherents of this view will not accept even the characterization of scientific and philosophical inquiry offered in the previous paragraph. For them, there is no truth-analogue that can straightforwardly be substituted for truth. We acknowledge that our claims about the burden of proof and truth-directed practices simply do not apply to science and philosophy viewed in this light. We would include science and philosophy so conceived with the non-truth-directed practices discussed in section 2 above. But it seems worth noting just how dramatically such views depart from the common understanding of endeavors such as science and philosophy. To the extent that an antirealist accepts our modest characterization of science and philosophy as having ideals of responsiveness to evidence and argument, he or she should accept some version of our claims about the burden of proof in these practices.

\section{Exceptions and Objections}

Before concluding, we attempt to anticipate and respond to a number of the more obvious objections to our view.

First, we have argued that in truth-directed practices it is normally improper to place a higher burden of proof on one side of a debate than on the other, because doing so amounts to allowing one view to stand as the default and not requiring argument or evidence in support of it, or at least not requiring as much evidence or argument in support of it as we require in 
support of opposing views. Our claim is that such differential allocation is not in general truth conducive. But, someone might object, sometimes excluding evidence is truth conducive. Sometimes less evidence is better than more. Here is an example. Orchestras want to hire the best available musicians. We might say that the audition process is truth directed-it seeks the correct answer to the question "Who is the best candidate?" In the 1970s it became widely accepted that hiring decisions were influenced by factors everyone agreed were irrelevant to that question, most obviously the applicant's gender, and many orchestras introduced blind auditions in which applicants played behind a screen. The introduction of blind auditions had a dramatic effect on hirings. ${ }^{7}$ The exclusion of confounding evidence increased the truth conduciveness of the audition process. We agree that such examples show that excluding evidence can be truth conducive. They do not count against our claim, however, since they do not show that systematically excluding or weighting evidence on one side of an issue, as endorsed by differential allocation of the burden of proof, is truth conducive.

Second, we have drawn fairly sharp distinctions between our cases, but we acknowledge that matters will often be less clearcut. One obvious example is the distinction we have drawn between science and safety cases. In some cases science cases will be safety cases. Recall the $H$. pylori case. Earlier, we used the reception of the discovery of $H$. pylori as an illustration of the illegitimate allocation of the burden of proof. There is, however, at least one thing to be said for those who persisted with the standard treatment longer than the ideal of science might seem to have recommended. A critic of the standard view of the $H$. pylori case puts the point so:

[U]nlike ... other dreaded microbial diseases... presumptive $H$. pylori gastritis or even peptic ulcer disease is not particularly dangerous. It was also eminently treatable by the 1980 s even without antibiotics and prior to any knowledge of $H$. pylori... The rate of complete healing ... after several weeks of treatment with potent inhibitors of acid production was about 95\% (Straus 1996). Symptomatic relief occurs within a couple of weeks (McFarland et al. 1990). Such treatment, moreover, is remarkably safe and free of side effects. The same cannot be said for ... the first widely used antibiotic for $H$. pylori. This and other proposed antibiotic treatments for $H$. pylori have unquestioned side effects, some of which mimic the symptoms of the very disease for which they are prescribed. (Atwood 2004, 6-7)

If this is correct, the $H$. pylori case has significant analogies to the safety cases discussed earlier. Physicians knew the potential benefits of existing treatments offered, they knew they were 
effective, they knew their risks and side effects. We suggested that the differential allocation of the burden of proof in safety cases was justified by the fact that truth was not all that mattered in such cases. We might draw the same conclusion about $H$. pylori. Since existing treatments were known to be effective and safe, it may have been legitimate to demand a higher burden of proof for the claims about an unknown, potentially less effective and less safe alternative. Some science cases, this is to say, are not purely concerned with truth. Other factors, such as safety, might also figure, and legitimize differential allocations of the burden of proof. Such a conclusion is consistent with our general claim that differential allocation is in general illegitimate in truth-directed practices and also serves to highlight that the real world might not be as neatly divided as our model.

It might be objected, however, (and thirdly) that there are genuine exceptions to our claim: that there are examples of truth-directed inquiry in which differential allocation of the burden of proof is legitimate and that not all such cases can be explained away as merely apparent (as where an established theory is confronted by a new alternative), or as instances of not purely truth-directed inquiry (as in the cases in which it turns out that science cases are also safety cases). We agree. In general, we have claimed, differential allocations of the burden of proof are illegitimate in truth-directed practices. We think there are exceptions. The exceptions, we believe, are cases in which differential allocation is truth conducive.

Suppose, for instance, that you are selling your car. You almost certainly know more about the car than potential purchasers: they may have taken it for a quick testdrive, you have been driving it regularly for many years. You know its quirks and its service record: they do not. You are surely better placed than they are to judge the condition of the vehicle. Typically, however, the buyer bears the burden of finding out whether or not there is anything wrong with the vehicle: caveat emptor. Why is this? Given the information asymmetry that typically marks such everyday transactions, why do most communities stand by the caveat emptor rule, and are they right to do so? The discussion in this paper highlights one significant and plausible answer to this question. Although the vendor typically has easier access to the truth about the car, the vendor is also the person who has the most obvious motive for failing to disclose that information. If communities are interested in agreements for the sale and purchase of goods being based on accurate information about those goods, they have reason to devise systems that increase the probability that that information will be bought into the open. Such systems typically include legislative and common law duties of disclosure and post-facto remedies for misrepresentation, but such provisions 
are expensive and inefficient. The caveat emptor rule trades on a buyer's incentive to seek the truth about goods she intends to buy, requiring buyers themselves to guard against nondisclosure and dishonesty, allowing states to avoid involvement in the countless small transactions that make up a typical market. The rule differentially allocates the burden of establishing the truth of claims about goods offered for sale, and so is an exception to our general claim. Note however, that it is an exception that reinforces the rationale behind that claim: the burden is differentially allocated in the caveat emptor case precisely because differential allocation is truth conducive in those cases.

The extent to which truth-conduciveness is driving institutional design in such exceptional cases may be reinforced by another, rather different example. We said earlier that in penal law, in general, the burden of proof is legitimately placed on the accuser as a means of protecting the rights of the accused. Income tax law is in significant respects penal, but most jurisdictions allocate the burden differently. It is up to taxpayers to prove their level of taxable income. If they are unwilling or unable to do so, the tax collector's assessment is taken to be correct. Not only is the standard legal allocation of the burden of proof reversed, resting upon the person against whom liability is asserted, but in contrast to the caveat emptor case, the burden is differentially allocated to the party who has access to truth, rather than to the party who has a motive to disclose it. Why is the burden differentially allocated in this way in tax cases? New Zealand's official Taxpayer Guidelines are typical, and say this:

The key reason for the onus of proof being on taxpayers is that facts about the tax positions they take are primarily within their knowledge. Moreover, it is the taxpayer who exercises primary control over record-keeping, and over the extent to which there is full and honest disclosure to Inland Revenue. (Policy Advice Division of the Inland Revenue Department 2001, 5.7 and 5.8)

We think the reversed allocation-from the state to the citizen and from the party with the motive to discover the truth to the party who has the easiest access-reinforces the conclusion that truth-conduciveness is the key factor in settling whether differential allocation is legitimate, and if so how it should be allocated. States are interested in the truth about their citizen's tax liability-they wish to collect neither more nor less than their entitlement. Having the burden track access is a way of achieving that goal. The tax and caveat emptor cases are genuine exceptions to our claim that differential allocation of the burden of proof is legitimate only in non-truth-directed practices. However, they are cases in which the differential allocation is legitimate precisely because, unusually, it is truth conducive. 


\section{Conclusion}

We have argued that those who assume the ubiquity of legitimate differential allocations of the burden of proof are mistaken. We hope to have shown that legitimate differential allocation is much less common than is typically supposed. The clearest examples are those in which truth is not the main aim. Legal contexts are one example. Contexts in which we do not mind being wrong so long as we err (if at all) in the direction of caution are another. Generalizing from the obvious usefulness of burden of proof allocations in such contexts is a mistake. In particular, the common tendency to move directly from the legitimacy of differential allocations in legal contexts to their legitimacy in general overlooks something important about the law, namely that its primary aim is something other than truth. The legitimacy of differential allocations depends on whether they tend toward the achievement of the aim of the practice in question. When the aim is truth, typically they do not do so. Whether differential allocations are legitimate depends on whether the practice in question is truth directed and, if it is, whether and what differential allocations are truth conducive in that practice. There are some special cases in which differentially assigning the burden of proof in truth-directed practices is truth conducive, but in general, in truth-directed inquiries, the burden of proof is on all of us alike. ${ }^{8}$

\section{Notes}

1 Of course, we are not the first to think so. For example Keith Lehrer remarks in passing that "generally arguments about where the burden of proof lies are unproductive. It is more reasonable to suppose that such questions are best left to courts of law where they have suitable application" (Lehrer 1978, 358).

2 Hence the lower burden of proof in civil cases, where-rightly or not-the law considers that the stakes are lower: the civil law tends to deal with "mere" monetary and property rights, rather than the traditionally more important rights directly associated with individual liberty.

3 Such proceedings would not have been straightforward under the law as it stands, but that does not count against our point: if the law were truly truth directed, it might be amended allow such proceedings more easily than it currently does.

4 Max Steuer gained an unlikely acquittal for his factory-owner clients in the infamous Triangle Shirtwaist Fire Case by destroying the credibility of a key witness, though no one seriously doubted that the facts were as the prosecution alleged. Seventy-five years after the fire, Daniel Kornstein wrote admiringly, "Steuer had to bring to bear all of his considerable skills... The undisputed facts-locked doors forcing scores of women, clothes and hair ablaze, to leap from windows to their deaths-made the defendants' prospects bleak. Surely this was a case that would result in convictions. But the ... prosecutor ... did not 
count on Steuer's ability" (Kornstein 1986, 2).

5 How far Marshall felt he had to go to make his case is shown by a remarkable incident in which he swallowed a concoction of $H$. pylori in order to induce gastritis in himself.

6 For an engaging treatment of the dangers of consensus science, see Michael Crichton 2003.

7 In 1970, 5 percent of musicians in the top five U.S. orchestras were women. By 1990, following the widespread use of blind auditions, that figure had increased to 25 percent. Economists Claudia Goldin and Celia Rouse (2000) argue that the switch to blind auditions can explain between 30 percent and 55 percent of the increase in the proportion of women among new hires and between 25 percent and 46 percent of the increase in the percentage of women in the orchestras since 1970.

8 Many thanks to all who have provided useful feedback on earlier versions of this paper: in particular David Braddon-Mitchell, Heather Dyke, Robert Nola, an anonymous referee for this journal, and audiences at the University of Queensland, the University of Auckland, Cornell Law School and the AAP(NZ) conference at the University of Otago.

\section{Bibliography}

Allen, Matthew. 2004. Smart thinking. 2 ed. Melbourne: Oxford University Press.

Atwood, Kimball. November 2004. Bacteria, ulcers, and ostracism?: Pylori and the making of a myth. Skeptical Inquirer.

Auckland Debating Association Guidelines. 2002. Available at http:// www.ada.org.nz/guidelns.php.

Bailenson, Jeremy. 2001. Contrast ratio: Shifting burden of proof in informal arguments. Discourse Processes 32:29-41.

Berkeley, George. 1971. A treatise concerning the principles of human knowledge (1734). Menston: Scholar Press.

Crichton, Michael. 2003. Aliens cause global warming. Caltech Michelin lecture, available at http://www.crichton-official.com/speeches/ index.html.

Goldin, Claudia, and Celia Rouse. 2000. Orchestrating impartiality: The impact of 'blind' auditions on female musicians. American Economic Review 90:715-41.

Handler, Jonathan A., James G. Adams, Craig F. Feied, Michael Gillam, John Vozenilek, Edward N. Barthell, and Steven J. Davidson. 2004. Developing consensus in emergency medicine information technology. Academic Emergency Medicine 11:1109-11.

Kornstein, Daniel. 1986. A tragic fire-A great cross examination. New York Law Journal, March 28.

Lehrer, Keith. 1978. Why not scepticism? In Essays on knowledge and justification, ed. George Pappas and Marshall Swain, 346-63. Ithaca: Cornell University Press.

McFarland, R. J., J. R. Bateson, R. B. Green et al. 1990. Omeprazole provides quicker symptom relief and duodenal ulcer healing than ranitidine. Gastroenterology 98:278-83.

Police v Fowlie 15/02/02 Gittos J, Auckland District Court. Available at http://www.norml.org.nz/Rights/chrisfowlieruling.htm.

Policy Advice Division of the Inland Revenue Department. 2001. 
Taxpayer compliance, standards and penalties: A review. Available at http://www.taxpolicy.ird.govt.nz/publications/files/html/taxpyrco/ index.html.

Putnam, Hilary. 1990. Reason, truth, and history. Cambridge: Cambridge University Press.

Räikkä, Juha. 2005. Global justice and the logic of the burden of proof. Metaphilosophy 36:228-39.

Reid, Thomas. 1863. The works of Thomas Reid. Edinburgh: MacLachlan and Stewart.

Scriven, Michael. 1966. Primary philosophy. New York: McGraw-Hill.

Straus, E. 1996. Duodenal ulcer. In Medicine for the practicing physician, ed. J. W. Hurst, 1583-85. Stamford, CT: Appleton and Lange.

van Fraassen, Bas. 1980. The scientific image. Oxford: Clarendon Press.

Wigmore, John Henry. 1976. Wigmore on evidence. 34th ed. Rev. J. T. McNaughton. Boston: Little, Brown.

Woolgar, Steve. 1988. Science: The very idea. London: Tavistock Publications. 
Copyright of Southern Journal of Philosophy is the property of Southern Journal of Philosophy and its content may not be copied or emailed to multiple sites or posted to a listserv without the copyright holder's express written permission. However, users may print, download, or email articles for individual use. 